\section{Not quite the full story on new antiplatelets}

Chua and Nishi's ${ }^{1}$ review of the new antiplatelets for acute coronary syndrome does not cite all of the relevant literature and fails to identify all of the issues related to ticagrelor and prasugrel.

Chua and Nishi ${ }^{1}$ did not reference the US Food and Drug Administration (FDA) medical review of ticagrelor. ${ }^{2}$ This comprehensive review considered both published and unpublished data from the PLATO trial. The FDA reviewers identified that the reduction in mortality reported by Chua and $\mathrm{Nishi}^{1}$ was present only in the non-US population, thus limiting the generalizability of this finding. Reviewers also identified irregularities surrounding the ascertainment of outcomes and participant follow-up times. Also, FDA reviewers state "[a] troubling observation in PLATO was the increased frequency and earlier time to overall stroke and intracranial hemorrhagic bleeding events (mostly from strokes) in the ticagrelor-treated patients ... and the relative risk of having a stroke or TIA for patients with pre-existent disease was 2 times higher for ticagrelor-treated patients than for clopidogrel-treated patients."

The FDA medical review of prasug$\mathrm{rel}^{3}$ was also omitted from Chua and Nishi's ${ }^{1}$ assessment. Several important safety signals arise from the FDA analysis. Chua and Nishi ${ }^{1}$ indicate that support for the new antiplatelets comes from "recent clinical guidelines." To characterize guidelines as supportive evidence is misleading, particularly when the cited guidelines ${ }^{4}$ do not report involving methodology experts in their primary guideline panel. ${ }^{5}$ Our final concern rests with the authors' ${ }^{1}$ seemingly definitive recommendations. The authors conclude that ticagrelor and prasugrel have a role in acute coronary syndrome, despite the fact that there is only one randomized controlled trial (RCT) for ticagrelor and two discordant RCTs for prasugrel. We suggest a more cautious conclusion is appropriate, namely that there is insufficient evidence for prasug- rel and ticagrelor to rule out serious harm or to characterize the benefit in patients with acute coronary syndrome.

Cait O'Sullivan PharmD BScPh BA, Aaron M. Tejani BSc (Pharm) PharmD Clinical pharmacist (O'Sullivan), Island Health Clinical Pharmacy Programs, BC Provincial Academic Detailing Service; Researcher (Tejani), Therapeutics Initiative, University of British Columbia, Vancouver, BC

\section{References}

1. Chua D, Nishi C. New antiplatelet agents for cardiovascular disease. CMAJ 2013;185:1405-11

2. Ticagrelor medical review. Silver Spring (MD): US Food and Drug Administration: Centre for Drug Evaluation and Research. Available: www.accessdata .fda.gov/drugsatfda_docs/nda/2011/022433Orig1s 000MedR.pdf (accessed 2014 Feb. 20).

3. Prasugrel medical review. Silver Spring (MD): US Food and Drug Administration: Centre for Drug Evaluation and Research. Available: www.accessdata .fda.gov/drugsatfda_docs/nda/2009/022307s000TOC .cfm (accessed 2014 Feb. 20)

4. Tanguay JF, Bell A, Ackman ML, et al. Focused 2012 update on the Canadian cardiovascular society guidelines for the use of antiplatelet therapy. Can J Cardiol 2013;29:1334-45.

5. Lenzer J, Hoffman J, Furberg CD, et al. Ensuring the integrity of clinical practice guidelines: a tool for protecting patients. BMJ 2013;347:f5535. 2013;29: $1334-45$

CMAJ 2014. DOI:10.1503/cmaj.114-0027

\section{The authors respond}

O'Sullivan and Tejani' provide an interesting perspective on our CMAJ review article. ${ }^{2}$ Because of geographic differences in the efficacy of ticagrelor, the FDA delayed approval of the drug twice and requested further data and analysis. ${ }^{3.4}$ Although the FDA document does identify some concerns, the manufacturer responses, an exhaustive review of additional data and reanalysis proved satisfactory for the FDA to finally approve ticagrelor in July 2011.

Not only do the Canadian Cardiovascular Society 2012 antiplatelet guidelines ${ }^{5}$ recommend prasugrel and ticagrelor over clopidogrel, but several other recent guidelines ${ }^{6,7,8}$ also recommend ticagrelor over clopidogrel. These guidelines are very clear and transparent about how recommendations were synthesized, about methodology and about what evidence was included. These guidelines are targeted toward clinicians, thus having clinicians on the primary panel is appropriate.
O'Sullivan and Tejani' advocate that clinical trials need to be replicated, and that we can't be certain of any early therapeutic benefit effect shown in only a single randomized controlled trial. Based on that premise, we should not be using aspirin for acute myocardial infarction. Twenty-five years ago, the landmark ISIS-2 trial showed the mortality benefit of early use of aspirin in acute myocardial infarction. ${ }^{9}$ This benefit has never been replicated in a randomized, properly powered clinical trial since ISIS-2.

We appreciate O'Sullivan and Tejani's ${ }^{1}$ concerns; however, no new drug or landmark trial is without its weaknesses and controversy. Clinicians should judge if the concerns surrounding the newer antiplatelet agents are sufficient to deny their patients more efficacious therapy.

\section{Doson Chua PharmD, Cesilia Nishi PharmD}

Department of Pharmacy (Chua, Nishi), St. Paul's Hospital, Vancouver, BC

\section{References}

1. O'Sullivan C, Tejani AM. Not quite the full story on new antiplatelets. CMAJ 2014;186:533.

2. Chua D, Nishi C. New antiplatelet agents for cardiovascular disease. CMAJ 2013;185:1405-11.

3. Ticagrelor medical review. Silver Spring (MD): US Food and Drug Administration: Centre for Drug Evaluation and Research. Available: www.accessdata .fda.gov/drugsatfda_docs/nda/2011/022433Orig1s 000MedR.pdf (accessed 2014 Feb. 20)

4. No US approval for ticagrelor yet; FDA requests further analysis of PLATO. Medscape. 2010 Dec. 17. Available: www.medscape.com/viewarticle/734465 (accessed 2014 Feb. 20).

5. Tanguay JF, Bell AD, Ackman ML, et al. Focused 2012 update of the Canadian Cardiovascular Society guidelines for the use of antiplatelet therapy. Can J Cardiol 2013;29:1334-45.

6. O'Gara PT, Kushner FG, Ascheim DD, et al. 2013 ACCF/AHA guideline for the management of STelevation myocardial infarction: a report of the American College of Cardiology Foundation/American Heart Association Task Force on Practice Guidelines [published erratum in Circulation 2013;128:e481] Circulation 2013;127:e362-425.

7. 2012 ESC guidelines on acute myocardial infarction (STEMI). Eur Heart J 2012;33:2501-2.

8. Vandvik O, Lincoff MA, Gore JM, et al. Primary and secondary prevention of cardiovascular disease: Antithrombotic Therapy and Prevention of Thrombosis, 9th ed: American College of Chest Physicians Evidence-Based Clinical Practice Guidelines [published erratum in Chest 2012;141:1129]. Chest 2012;141(Suppl 2);e637S-e68S.

9. Randomised trial of intravenous streptokinase, ora aspirin, both, or neither among 17187 cases of suspected acute myocardial infarction: ISIS-2. ISIS-2 (Second International Study of Infarct Survival) Collaborative Group. Lancet 1988;2:349-60.

CMAJ 2014. DOI:10.1503/cmaj.114-0028 